This is the final peer-reviewed accepted manuscript of:

"A facile hydroxylation of arylboronic acids mediated by sodium ascorbate". Gualandi, A.; SAVOINI, A.; Saporetti, R.; Franchi, P.; Lucarini, M.; Cozzi, P. G. Org. Chem. Front., 2018,5, 1573-1578.

The final published version is available online at: https://doi.org/10.1039/C8Q000061A

Rights / License:

The terms and conditions for the reuse of this version of the manuscript are specified in the publishing policy. For all terms of use and more information see the publisher's website.

This item was downloaded from IRIS Università di Bologna (https://cris.unibo.it/)

When citing, please refer to the published version. 



\title{
A facile hydroxylation of arylboronic acids mediated by sodium ascorbate $\uparrow$
}

\author{
Andrea Gualandi, Andrea Savoini, Roberto Saporetti, Paola Franchi, \\ Marco Lucarini (D) and Pier Giorgio Cozzi (D) \\ A simple, direct and facile hydroxylation of arylboronic acids has been described. The reaction is carried \\ out under air, in an open flask, using 2 equivalents of sodium ascorbate. A variety of arylboronic acids can \\ be transformed into the corresponding phenols in excellent to moderate isolated yields. The reaction tol- \\ erated the presence of functional groups, and molecules that are readily oxidized by $\mathrm{H}_{2} \mathrm{O}_{2}$ can be present \\ in the reaction mixture. This green methodology avoids the use of photoredox conditions, transition \\ metals, or other strong oxidants.
}

Phenols are important intermediates and materials that can be found as constituents in natural products ${ }^{1}$ and pharmaceutical compounds, ${ }^{2}$ as the phenolic hydroxyl is widely present in these classes of compounds. A straightforward access to phenols is represented by the hydroxylation of arylboronic acids, ${ }^{3}$ one of the most versatile building blocks with more than four thousand being commercially available. ${ }^{4}$ Different approaches have been introduced to realize this transformation based on metal catalysis ${ }^{5}$ under various conditions. Normally, these transformations are carried out in the presence of a stoichiometric amount of an oxidant. ${ }^{6}$ With the aim to reduce waste, different methodologies that avoid the stoichiometric use of an oxidant were developed, for example, electrochemical methods were successfully applied. ${ }^{7}$ In particular, it has been recently reported that hydroxylation of arylboronic acids to phenols is possible by a scalable electrocatalytic method that employs methyl viologen as an organic cathodic electrocatalyst, and involves $\mathrm{O}_{2}$ as a green and sustainable reactant. ${ }^{8}$ Recently, photoredox catalysis ${ }^{9}$ has attracted considerable attention as it gives the possibility of creating catalytic species that act as a strong oxidant and reductant in the excited state. In these processes the photocatalyst can be recovered to the initial state by fine tuning of the redox couple involved in the process. Interestingly, organocatalytic aerobic methodologies that avoid the use of metals

Dipartimento di Chimica “G. Ciamician”, ALMA MATER STUDIORUM Università di Bologna, Via Selmi 2, 40126 Bologna, Italy.E-mail: andrea.gualandi10@unibo.it, piergiorgio.cozzi@unibo.it

$\dagger$ Electronic supplementary information (ESI) available: Experimental procedures, product characterization, NMR spectra, and compound preparation procedures. See DOI: 10.1039/c8qo00061a and photocatalysts have also been reported..$^{10}$ Often, a sacrificial oxidant or reductant is used to close the catalytic cycle. ${ }^{11}$ Photoredox promoted hydroxylation of arylboronic acids was described by using photoredox metal catalysts such as ruthenium and iron, ${ }^{12}$ or employing photoredox organic molecules. ${ }^{13}$ Although these new procedures avoid the use of stoichiometric oxidants, the formation of phenols is induced by carrying out the photoredox reaction in the presence of oxygen or air, which is the true oxidant of the reaction. Furthermore, these quite interesting transformations could be scaled-up with difficulties, as the problem is related to light sources and reactors. The employment of flow-conditions in photoredox catalysis can be used to address limitations and for scaling up, ${ }^{14}$ even though the need for special equipment and expertise for setting up these reactions can lower the interest in these attractive methodologies.

Herein, we report a facile, high yielding, and straightforward methodology for the direct transformation of boronic acids and esters into the corresponding phenols. The reaction is carried out in air, it tolerates the presence of all functional groups, it is specific and, importantly it uses just 2 equivalents of the inexpensive ascorbate as a mediator for the redox process.

\section{Results and discussion}

Ascorbate is generally considered as a reductant ${ }^{15}$ and its use as an antioxidant has been well reported in the literature. ${ }^{16}$ Ascorbate facilitates the reduction of peroxide and it is used for "click" chemistry, ${ }^{17}$ and has the ability to reduce $\mathrm{Cu}$ (II) to active $\mathrm{Cu}(\mathrm{I})$ for alkyne-azide cycloadditions. ${ }^{18}$ Quite recently, a novel and green method for the ipso-hydroxylation of arylboronic acids with ascorbate and a quinone (vitamin K3 or menadione) has been reported. ${ }^{19}$ 
Hydrogen peroxide generated in situ by this method has been proven to act efficiently as an oxidant of arylboronic acids and a few other organic moieties. Indeed, vitamin $\mathrm{C}$ is a mild, inexpensive and non-toxic reducing agent, rarely used in organic synthesis. As ascorbate can promote quinone redox recycling, the authors have used ascorbate to reduce the quinone to the corresponding radical anion, that is able to donate $\mathrm{H}^{+}$and an electron to oxygen, forming the intermediate $\mathrm{HOO}^{-}$. This species is able to generate the oxidant for this reaction, $\mathrm{H}_{2} \mathrm{O}_{2}$, by disproportion or by reduction carried out by another molecule of ascorbate. The presence of hydrogen peroxide, produced from the oxygen of air, was confirmed by the authors. In addition, a flavin-catalysed oxidative hydroxylation of substituted arylboronic acids to phenols by molecular oxygen, using hydrazine or ascorbic acid was also described. ${ }^{20}$ The reaction in this case occurred by the formation of preflavin hydroperoxide. However, the presence of flavin is not crucial for this kind of reaction, as the transformation can be carried out in an efficient manner with sub-stoichiometric quantities (50 mol\%), in poly(ethylene glycol) (PEG-400) as the reaction solvent, and using 2 equivalents of $\mathrm{Cs}_{2} \mathrm{CO}_{3}$ as base. ${ }^{21}$ Ascorbate has also found an interesting application as a sacrificial reductant in photoredox mediated processes. ${ }^{22}$ Recently, we have been able to use BODIPY dyes for ATRA reaction ${ }^{23}$ employing sodium ascorbate as a sacrificial reductant for BODIPY in its excited state. To expand the scope of this chemistry we have explored the use of this and other organic dyes under photoredox conditions for the synthesis of phenols starting from the corresponding arylboronic acids. Quite surprisingly, when the model reaction was performed in the absence of light but in the presence of sodium ascorbate we found that the transformation was possible. It is noteworthy that ascorbate and ascorbate solutions are stable towards oxygen and are not able to directly reduce dioxygen. At the same time, we became aware of a report in the literature that has described the catalyzed oxidation of vinylic boronic acid by ascorbate for bioconjugation. ${ }^{24}$ The authors have also proven that phenylboronic acid was transformed into a phenol, but quantitative studies were not reported. Independently, we have found that sodium ascorbate can be a suitable reagent for the transformation of arylboronic acids into the corresponding substituted phenols giving a clean transformation, without the need for mediators or quinones. In order to optimize the process, we have carried out the model reaction with 4-methoxyphenylboronic acid $\mathbf{1 a}$ and sodium ascorbate, investigated different solvents and stoichiometries, and found that the reaction of 1a carried out in an open flask in DMF gave a clean and quantitative transformation of $1 \mathbf{a}$ to the corresponding 4-methoxyphenol 2a (Table 1, entry 15 , yield 95\%). The product formation was not observed after careful exclusion of oxygen under the ambient reaction atmosphere (Table 1, entry 16) whereas under an oxygen atmosphere (Table 1, entry 17) the reaction gave the same result as that observed in the presence of air.

Pinacol aryl borane 3 (Fig. 1) was investigated under the optimized reaction conditions and we found that boronic
Table 1 Screening of reaction conditions for the hydroxylation of arylboronic acid 1a

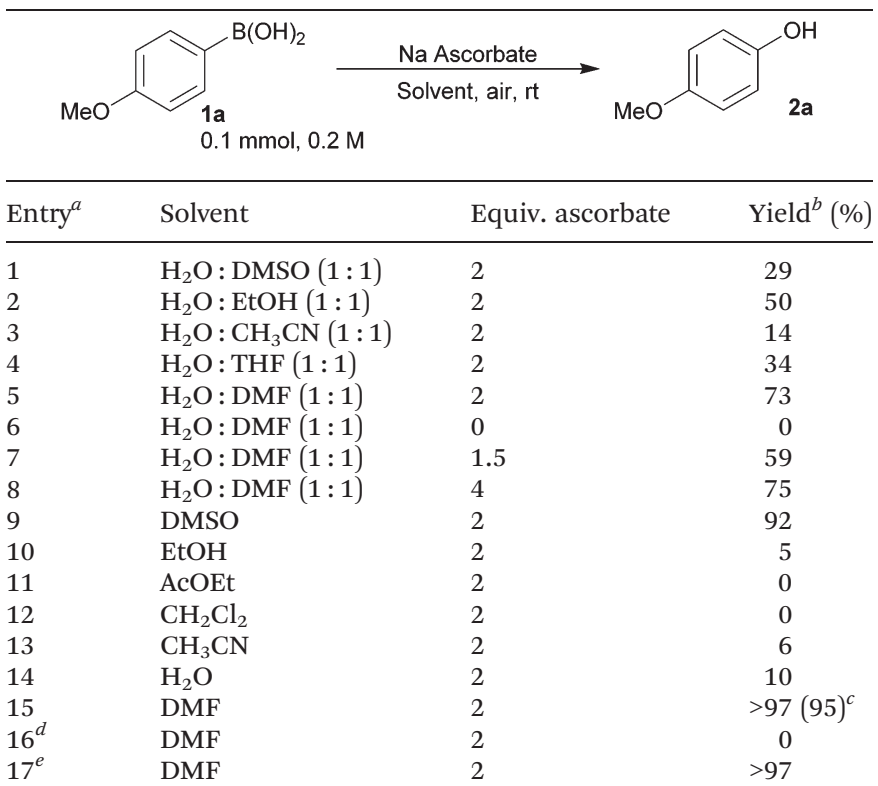

${ }^{a}$ All the reactions were carried out using $0.1 \mathrm{mmol}$ of $1 \mathrm{a}$ and 2 equiv. of sodium ascorbate in $0.5 \mathrm{~mL}$ of solvent at $\mathrm{rt}$ for 18 hours. ${ }^{b}$ Determined by ${ }^{1} \mathrm{H}$-NMR of the crude reaction mixture. ${ }^{c}$ Yield was determined after chromatographic purification. ${ }^{d}$ Reaction was performed under an argon atmosphere with degassed solvent. ${ }^{e}$ Reaction was performed under an oxygen atmosphere.

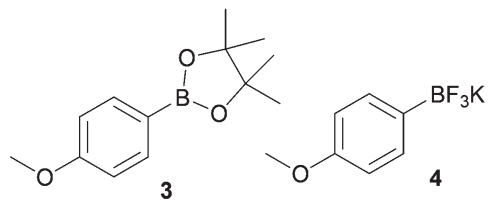

Fig. 1 Arylboronic acid derivatives tested in the oxydation reaction.

esters were also suitable substrates for the transformation. However potassium aryltrifluoroborate 4 was found to be completely unreactive. Ascorbic acid and ascorbic acid 6-palmitate are able to mediate the reaction of oxidation of $1 \mathrm{a}$ with comparable results to sodium ascorbate.

The scope of the transformation was investigated by using commercially available or readily prepared arylboronic acid (Scheme 1). ${ }^{25}$

The reaction is successful with electron rich and electron poor arylboronic acids giving the desired products in good yields. The work-up is quite straightforward as it consists of dilution with water and organic solvents followed by extraction. The sodium ascorbate and products derived from its oxidation are soluble in water, and the phenol is isolated by extraction using an organic solvent. From the NMR of the crude reaction mixture we observed in many cases an extremely clean reaction. Only with 9-phenanthreneboronic acid 1d, 4-isoquinolineboronic acid 1r and 2-thiopheneboronic acid 1t the yields were inferior, due to the presence of by-products. 


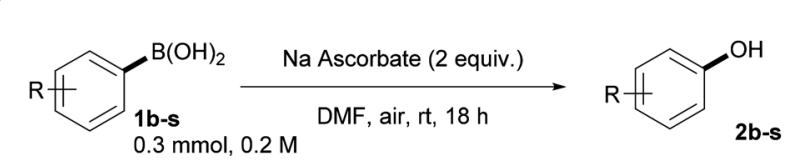

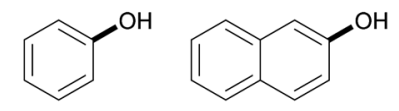

2b, $92 \%$<smiles>Oc1ccc(Cl)cc1Cl</smiles>

2h, $72 \%$<smiles>CC(=O)c1ccc(O)cc1</smiles>

2c, $89 \%$<smiles>[Z10][R6]</smiles>

2i, $98 \%$

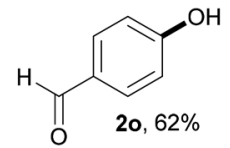<smiles>CCc1cc2ccccc2cc1O</smiles>

2d, $46 \%$<smiles>COc1cccc(OC)c1O</smiles>
2j, $76 \%$<smiles>CN(C)c1cccc(O)c1</smiles><smiles>Oc1ccc(-c2ccccc2)cc1</smiles>

2e, $96 \%$<smiles>[Z10][Ba]</smiles>

2f, $81 \%$<smiles>Oc1ccc(Br)cc1</smiles>

2g, $68 \%$<smiles>COc1ccc(O)c(C)c1</smiles><smiles>COC(=O)c1ccc(O)cc1</smiles><smiles>Oc1cccnc1</smiles><smiles>Oc1cncc2ccccc12</smiles><smiles>O=[N+]([O-])c1ccccc1O</smiles><smiles>Oc1cccs1</smiles>

2t, $0 \%$

Scheme 1 Oxidation of different arylboronic acids.

In the case of phenanthrene derivative $\mathbf{2 d}$, over oxidation of the aromatic compound, to the corresponding quinone derivative, was detected. The over oxidation and instability are determined by the presence of air in the reaction mixture. Finally, hydroxythiophene $\mathbf{2 t}$ is unstable under the reaction conditions and unidentified opened products can be recognized by NMR and GC analysis. Arylboronic acids carrying strong electron withdrawing groups, as in the case of the substrate $1 \mathrm{~s}$, are not suitable substrates for the transformation, as they cause instability of the intermediate formed (vide infra for mechanistic investigations). In the reactions of $\mathbf{1} \mathbf{g}$ and $\mathbf{1 h}$ the low yields obtained were due to partial sublimation of phenol derivatives during removal of solvents under reduced pressure.

We assessed the robustness of the methodology by investigation of the compatibility of this reaction with chemical functionalities and structural motifs (Scheme 2). ${ }^{26}$ The substrate $\mathbf{1 k}$ was mixed with 1 equiv. of various "additives" carrying different functional groups and the yield of product $2 \mathbf{k}$ and the stability of additives after the reaction were determined. The reaction was carried out in the presence of chalcone 5, 4-phenyl-1butene 6, Fmoc-Ser-OMe 7, Fmoc-Trp-OMe 8, 2',3',5'-triacetylguanosine 9, pregnenolone 10 and benzyl alcohol 11. In all the cases, ${ }^{1} \mathrm{H}-\mathrm{NMR}$ and HPLC-MS analysis have shown that the oxidation reaction takes place in the presence of the other functional groups present in many biologically active molecules. The phenol $\mathbf{2 k}$ was obtained in all cases in quantitative yields and in all the reactions no by-products were observed. It is important to mention that epoxidation of electron poor (e.g. chalcone and pregnenolone) or electron rich (e.g. 4-phenyl-1-butene) alkenes was not observed. The reaction is compatible with sensitive protected aminoesters such as tryptophan or serine derivatives.

The mechanism of the reaction is quite intriguing, as sodium ascorbate is stable under dioxygen, and is not oxidized by air. The ability of ascorbate to reduce arylboron compounds
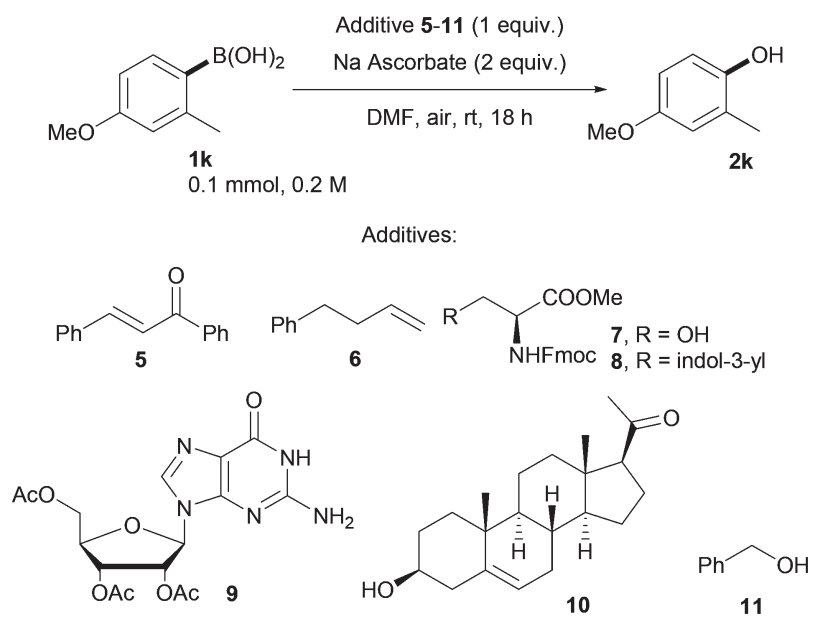

Scheme 2 Tests for the robustness of the methodology.

to the corresponding boryl radicals, able to interact with dioxygen, cannot be considered feasible because of the high reduction potential necessary for obtaining these unstable and reactive species. ${ }^{27}$ However, it has been reported in the literature that an electrochemically produced ascorbyl radical avoided the kinetic barrier that prevented direct oxidation of ascorbic acid with oxygen and eliminated the need for transition metal ion catalysts. ${ }^{28}$ We have indeed observed a considerable increasing of the ascorbyl radical concentration by EPR (see Fig. 2) when phenylboronic acid is present in the reaction mixture. Instead, only traces of ascorbyl radicals are formed under oxygen in solution.

Furthermore, when the model reaction was performed in the presence of $30 \mathrm{~mol} \%$ of EDTA sodium salt, we have observed a full conversion (checked by NMR) of compound $\mathbf{1 a}$. 


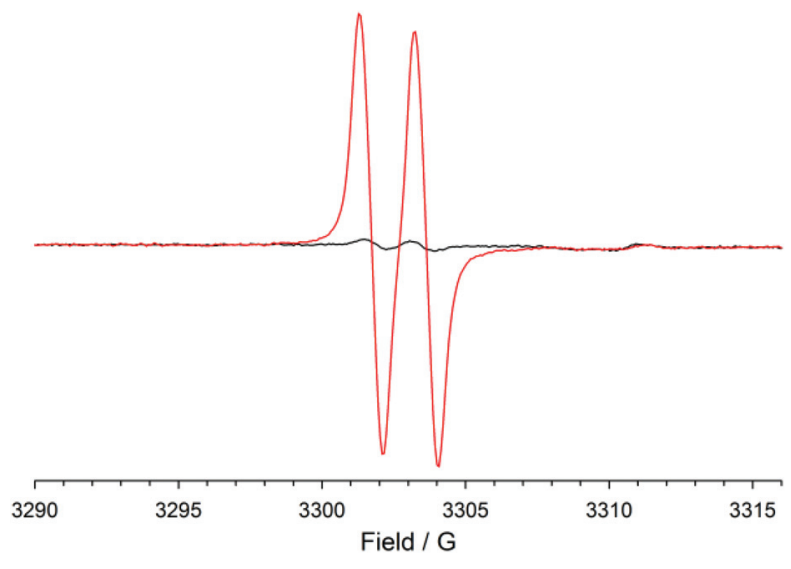

Fig. 2 EPR spectra of ascorbate radical anion recorded in DMF in the absence (black line) and in the presence of $1 \mathrm{a} 0.2 \mathrm{M}$ (red line). ${ }^{2}$

Traces of metals (i.e. iron) present in the reaction mixture, able to catalyse the formation of $\mathrm{H}_{2} \mathrm{O}_{2}$, seem to play no role in this reaction. $^{28}$ As boronic acids can form reversible covalent bonds with 1,2- or 1,3-diols to generate five- or six-membered cyclic complexes, ${ }^{29}$ a compelling hypothesis for the oxidation could be related to the complexation of ascorbate to the arylboronic acid, followed by an electron transfer to oxygen. However, materials functionalized with boronic acid for chemo/biosensing ${ }^{30}$ are compatible with the presence of ascorbate, that does not interfere in the binding of the measured substrate with arylboronic acids supported on material. ${ }^{31}$ A more compelling hypothesis about the mechanism of the reaction came from an interesting recent work published by Liu and co-workers. ${ }^{8}$ Electrochemical mechanistic and kinetic studies conducted by the authors were able to characterize the presence of an arylboronic acid- $\mathrm{O}_{2}$ adduct, instead of $\mathrm{O}_{2}$, detected as the actual substrate of the reactions. The coordination of oxygen by the boronic acids proved to reduce the potential necessary for the formation of superoxide $\mathrm{O}_{2}{ }^{--}$ species linked to the boronate. In our reaction, the coordinated oxygen to $\operatorname{ArB}(\mathrm{OH})_{2}$ (I, Scheme 3) is reduced by ascorbate to give hydroperoxoboronate II. Upon the formation of the $\mathrm{OOH}$ coordinated species $\mathrm{ArOH}$ is obtained by migration of the aryl on the oxygen. As an alternative expla-

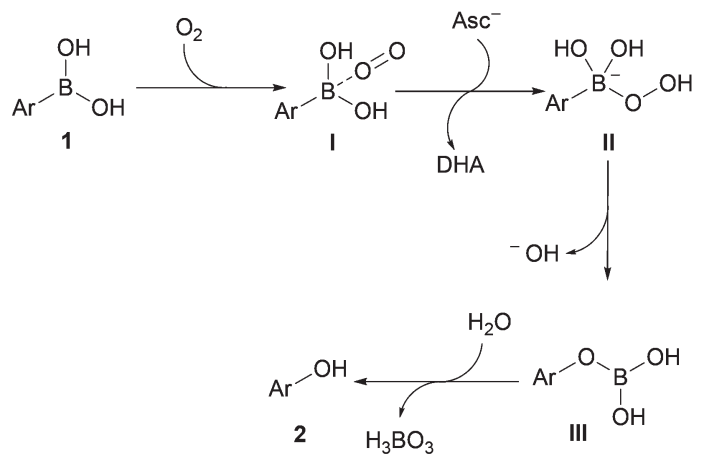

Scheme 3 Proposed reaction mechanism. nation for the formation of transient $\mathrm{O}_{2}{ }^{\cdot-}$, the autoxidation of ascorbate can be invoked. ${ }^{32}$ The superoxo species is then reduced by the ascorbate radical anion $\mathrm{AscH}^{--}$forming dehydroascorbic acid (DHA) and $\mathrm{HOO}^{-}$, that takes part in the oxidation of boronic acid. The generation of $\mathrm{HOO}^{-}$is also possible by disproportion of superoxide $\mathrm{O}_{2}{ }^{-}$in the presence of an acid donor. ${ }^{33}$ However, if $\mathrm{HOO}^{-}$is formed in the reaction mixture, its concentration is quite low, as Michael acceptors are compatible with the reaction. The $E_{1 / 2}$ value reported for the dehydroascorbate potential (DHA $+2 \mathrm{e}^{-}+\mathrm{H}^{+} \rightarrow \mathrm{Asc}^{-}$) is $+0.35 \mathrm{~V}^{34}$ Molecular oxygen coordinated to phenylboronic acid reduced at $-0.92 \mathrm{~V}\left(v s\right.$. $\left.\mathrm{Cp}_{2} \mathrm{Fe}^{+/ 0}\right),{ }^{8}$ that is $0.4 \mathrm{~V}$ less compared to a saturated solution of oxygen in DMF. For comparison, $p-\mathrm{NO}_{2} \mathrm{C}_{6} \mathrm{H}_{4} \mathrm{~B}(\mathrm{OH})_{2}$ is characterized by a reduction potential of $-1.95 \mathrm{~V}\left(v s . \mathrm{Ag}^{0 /+}\right) .{ }^{35}$ Boronic acids have high oxidation potentials, and normally strong stoichiometric oxidants or anodic oxidation are necessary. ${ }^{36}$ Recently, Ley reported the use of Lewis bases to alter the oxidation potentials. ${ }^{37}$ The authors obtained the value of $E_{1 / 2}=+0.81 \mathrm{~V}$ ( $v s$. SCE) by cyclic voltammetric measurements for the oxidation of a boronic pinacol ester.

The coordination of oxygen and its successive reduction mediated by ascorbate seems a more likely mechanistic scenario. ${ }^{38}$ It is also worth mentioning that in the hydrazine hydrate-mediated aerobic oxidation of aryl/heteroaryl boronic acids to phenol promoted by air, ${ }^{21}$ the authors reported that molecular oxygen was the oxidant, and that the reaction occurred indirectly, presumably by activation of the oxygen by the hydrogen bond of the hydrazine hydrate. Finally, as previously stated, the complexation of ascorbate free hydroxyl alcohol groups by boronic acid seems not to preclude the selective and favoured complexation of amines. ${ }^{31}$ We have observed using ${ }^{11} \mathrm{~B}$ NMR the formation of a new boronate species (see the ESI $\dagger$ ), probably due to a complex between arylboronic acid and oxygen (I or II in Scheme 3). It is worth mentioning that ascorbate is not soluble in the organic solvents used for the reaction, and the reaction is conducted in a heterogeneous mixture. It was claimed that the peptide boronic acid derivative 2-Pyz-(CO)-Phe-Leu- $\mathrm{B}(\mathrm{OH})_{2}$ (pyz = pyrazine), a potent inhibitor of $20 \mathrm{~S}$ proteasome, was degraded in the presence of ascorbic acid due to production of hydrogen peroxide, ${ }^{39}$ but we have not observed any reaction of Michael acceptors, when the model reaction was performed in the presence of chalcone 5, that is able to react with $\mathrm{H}_{2} \mathrm{O}_{2}$ in a Michael-type reaction. In order to check the possible formation of $\mathrm{HOO}^{-}$a test with potassium iodide starch paper was performed but we do not have strong evidence of the presence of $\mathrm{H}_{2} \mathrm{O}_{2}$ and this is another indication for the transient and direct reduction of coordinated $\mathrm{O}_{2}$.

\section{Conclusions}

In conclusion we have developed a clean and efficient oxidation of arylboronic acids by using ascorbate in the presence of oxygen. The reaction is quite mild and tolerates functional 
groups. No overoxidation of sensitive groups is observed and the reaction could be carried out in the presence of species that are sensitive to oxidation. Generally good yields and clean reactions were observed for this protocol. The intriguing behaviour of ascorbate, normally considered an antioxidant in organic chemistry is peculiar and can guide further application of its properties towards other selective oxidative processes.

\section{Experimental}

\section{Typical procedure}

To a $25 \mathrm{~mL}$ round bottom flask in open air, arylboronic acid (0.3 mmol), sodium ascorbate $(0.6 \mathrm{mmol}, 0.119 \mathrm{~g})$ and DMF $(1.5 \mathrm{~mL})$ were added. The suspension was vigorously stirred for $18 \mathrm{~h}$, and it was diluted with water $(10 \mathrm{~mL})$ and extracted with ethyl acetate $(3 \times 10 \mathrm{~mL})$. The combined organic layers were washed with brine $(10 \mathrm{~mL})$, dried over $\mathrm{Na}_{2} \mathrm{SO}_{4}$, and the solvent was removed under reduced pressure. Title compounds were purified by column chromatography on $\mathrm{SiO}_{2}$ using a cyclohexane/ethyl acetate mixture as an eluent.

\section{Conflicts of interest}

There are no conflicts to declare.

\section{Acknowledgements}

Bologna University, Fondazione Del Monte, and SLAMM project are acknowledged for financial support.

\section{Notes and references}

1 M. D. Kärkäs, Jr., J. A. Porco and C. R. J. Stephenson, Chem. Rev., 2016, 116, 9683.

2 Z. Rappoport, The Chemistry of Phenols, Wiley-VCH, Weinheim, 2003.

3 R. E. Maleczka Jr., F. Shi, D. Holmes and M. R. Smith III, J. Am. Chem. Soc., 2003, 125, 7792.

4 (a) D. G. Hall, Boronic Acids: Preparation and Applications in Organic Synthesis, Medicine and Materials, Wiley-VCH, Weinheim, 2nd edn, 2011, vol. 1; (b) T. Kalliokoski, ACS Comb. Sci., 2015, 17, 600.

5 Copper: (a) D. Yang, B. An, W. Wei, M. Jiang, J. You and H. Wang, Tetrahedron, 2014, 70, 3630; (b) A. Affrose, I. A. Azath, A. Dhakshinamoorthy and K. Pitchumani, J. Mol. Catal. A: Chem., 2014, 395, 500; (c) B. A. Dar, P. Bhatti, A. P. Singh, A. Lazar, P. R. Sharma, M. Sharma and B. Singh, Appl. Catal., A, 2013, 466, 60; (d) J. Zheng, S. Lin, X. Zhu, B. Jiang, Z. Yang and Z. Pan, Chem. Commun., 2012, 48, 6235; (e) L. Wang, W. Zhang, D. Sheng Su, X. Meng and F.-S. Xiao, Chem. Commun., 2012, 48, 5476; ( $f$ ) H. Yang, Y. Li, M. Jiang, J. Wang and H. Fu, Chem.
-Eur. J., 2011, 17, 5652; (g) K. Inamoto, K. Nozawa, M. Yonemoto and Y. Kondo, Chem. Commun., 2011, 47, 11775; (h) A. D. Chowdhury, S. M. Mobin, S. Mukherjee, S. Bhaduri and G. K. Lahiri, Eur. J. Inorg. Chem., 2011, 3232; (i) J. Xu, X. Wang, C. Shao, D. Su, G. Cheng and Y. Hu, Org. Lett., 2010, 12, 1964. Ruthenium: N. Gogoi, P. K. Gogoi, G. Borah and U. Bora, Tetrahedron Lett., 2016, 57, 4050. Silver: $(j)$ T. Begum, A. Gogoi, P. K. Gogoi and U. Bora, Tetrahedron Lett., 2015, 56, 95.

6 Hydrogen peroxide: for recent examples, see: (a) S. Gupta, P. Chaudhary, V. Srivastava and J. Kandasamy, Tetrahedron Lett., 2016, 57, 2506; (b) L. Wang, D.-y. Dai, Q. Chen and M.-y. He, J. Fluorine Chem., 2014, 158, 44; (c) G. Ä. S. Prakash, S. Chacko, C. Panja, T. E. Thomas, L. Gurung, G. Rasul, T. Mathew and G. Ä. Olah, Adv. Synth. Catal., 2009, 351, 1567. tert-Butylhydroperoxide (TBHP): (d) S. Guo, L. Lu and H. Cai, Synlett, 2013, 1712. m-CPBA: (e) D.-S. Chen and J.-M. Huang, Synlett, 2013, 499. Oxone: $(f)$ K. S. Webb and D. Levy, Tetrahedron Lett., 1995, 36, 5117; $(g)$ B. R. Travis, B. P. Ciaramitaro and B. Borhan, Eur. J. Org. Chem., 2002, 3429; (h) R. E. Maleczka, Jr., F. Shi, D. Holmes and M. R. Smith III, J. Am. Chem. Soc., 2003, 125, 7792; (i) G. A. Molander and L. N. Cavalcanti, J. Org. Chem., 2011, 76, 623. Hydroxylamine: $(j)$ E. Kianmehr, M. Yahyaee and K. Tabatabai, Tetrahedron Lett., 2007, 48, 2713. Amine oxide: (k) C. Zhu, R. Wang and J. R. Falck, Org. Lett., 2012, 14, 3494. Ozone: (l) Y. K. Bommegowda, N. Mallesha, A. C. Vinayaka and M. Sadashiva, Chem. Lett., 2016, 45, 268. $\mathrm{PhI}(\mathrm{OAc})_{2}$ : (m) A. Paul, D. Chatterjee, T. Rajkamal, T. Halder, S. Banerjee and S. Yadav, Tetrahedron Lett., 2015, 56, 2496; (n) N. Chatterjee, H. Chowdhury, K. Sneh and A. Goswami, Tetrahedron Lett., 2015, 56, 172; (o) J. S. Ruso, N. Rajendiran and R. S. Kumaran, Tetrahedron Lett., 2014, 55, 2345. Benzoquinone: $(p)$ G. Cheng, X. Zeng and X. Cui, Synthesis, 2014, 295. $\mathrm{NaClO}_{2}$ : (q) P. Gogoi, P. Bezboruah, J. Gogoi and R. C. Boruah, Eur. J. Org. Chem., 2013, 7291.

7 (a) K. Hosoi, Y. Kuriyama, S. Inagi and T. Fuchigami, Chem. Commun., 2010, 46, 1284; (b) H. Jiang, L. Lykke, S. U. Pedersen, W.-J. Xiao and K. A. Jørgensen, Chem. Commun., 2012, 48, 7203; (c) H.-L. Qi, D.-S. Chen, J.-S. Ye and J.-M. Huang, J. Org. Chem., 2013, 78, 7482.

8 J. Luo, B. Hu, A. Sam and T. Leo Liu, Org. Lett., 2018, 20, 361-364.

9 (a) T. P. Yoon, M. A. Ischay and J. Du, Nat. Chem., 2010, 2, 527; (b) J. M. R. Narayanam and C. R. J. Stephenson, Chem. Soc. Rev., 2011, 40, 102.

10 (a) A. N. Cammidge, V. H. M. Goddard, C. P. J. Schubert, H. Gopee, D. L. Hughes and D. Gonzalez-Lucas, Org. Lett., 2011, 13, 6034-6037; however, this methodology is limited to oxidation of alkoxynaphthylboronic acids.

11 C. K. Prier, D. A. Rankic and D. W. C. MacMillan, Chem. Rev., 2013, 113, 5322.

12 (a) Y.-Q. Zou, J.-R. Chen, X.-P. Liu, L.-Q. Lu, R. L. Davis, K. A. Jørgensen and W.-J. Xiao, Angew. Chem., Int. Ed., 2012, 51, 784; (b) X. Yu and S. M. Cohen, Chem. Commun., 2015, 51, 9880 . 
13 Methylene blue: (a) S. P. Pitre, C. D. McTiernan, H. Ismaili and J. C. Scaiano, J. Am. Chem. Soc., 2013, 135, 13286. Quinine: 2-chloroanthraquinone: $(b)$ T. Toyao, N. Ueno, K. Miyahara, Y. Matsui, T.-H. Kim, Y. Horiuchi, H. Ikeda and M. Matsuoka, Chem. Commun., 2015, 51, 16103; (c) M.-J. Zhang, H.-X. Li, H.-Y. Li and J.-P. Lang, Dalton Trans., 2016, 45, 17759; (d) X. Yu and S. M. Cohen, Chem. Commun., 2015, 51, 9880; (e) J. Luo, X. Zhang and J. Zhang, ACS Catal., 2015, 5, 2250; (f) J. A. Johnson, J. Luo, X. Zhang, Y.-S. Chen, M. D. Morton, E. Echeverría, F. E. Torres and J. Zhang, ACS Catal., 2015, 5, 5283; (g) 3(10H)-acridones: H.-Y. Xie, L.-S. Han, S. Huang, X. Lei, Y. Cheng, W. Zhao, H. Sun, X. Wen and Q.-L. Xu, J. Org. Chem., 2017, 82, 5236; (h) J. M. Tobin, T. J. D. McCabe, A. W. Prentice, S. Holzer, G. O. Lloyd, M. J. Paterson, V. Arrighi, P. A. G. Cormack and F. Vilela, ACS Catal., 2017, 7, 4602. 2,2-Dimethoxy-2-phenylacetophenone: (i) I. K. Sideri, E. Voutyritsa and C. G. Kokotos, Synlett, 2018, DOI: 10.1055/s-0036-1591837.

14 I. G.: T. M. Penders, Z. Amara, R. Horvath, K. Rossen, M. Poliakoff and M. W. George, RSC Adv., 2015, 5, 6501.

15 (a) E. Pelizzetti, E. Mentastic and E. Pramauro, Inorg. Chem., 1978, 17, 1181; (b) C. V. Krishnan and N. J. Sutin, J. Am. Chem. Soc., 1981, 103, 2141; (c) C. Creutz, Inorg. Chem., 1981, 20, 4449 and references therein.

16 For the uses in synthesis, see: (a) F. P. Crisóstomo, T. Martín and R. Carrillo, Angew. Chem., Int. Ed., 2014, 53, 2181; (b) D. L. Browne, I. R. Baxendale and S. V. Ley, Tetrahedron, 2011, 67, 10296.

17 Usually ascorbate has been extensively used to reduce mainly $\mathrm{Cu}(\mathrm{II})$ to $\mathrm{Cu}(\mathrm{I})$ for the CuCAAC "click" reaction; see: H. C. Kolb, M. G. Finn and K. B. Sharpless, Angew. Chem., Int. Ed., 2001, 40, 2004.

18 V. V. Rostovtsev, L. G. Green, V. V. Fokin and K. B. Sharpless, Angew. Chem., Int. Ed., 2002, 41, 2596.

19 G. Silveira-Dorta, D. M. Monzón, F. P. Crisóstomo, T. Martín, V. S. Martín and R. Carrillo, Chem. Commun., 2015, 51, 7027.

20 H. Kotoučová, I. Strnadová, M. Kovandová, J. Chudoba, H. Dvořákovác and R. Cibulka, Org. Biomol. Chem., 2014, 12, 2137-2142.

21 Y. Zhong, L. Yuan, Z. Huang, W. Gu, Y. Shao and W. Han, RSC Adv., 2014, 4, 33164-33167.

22 (a) C.-J. Wallentin, J. D. Nguyen, P. Finkbeiner and C. R. J. Stephenson, J. Am. Chem. Soc., 2012, 134, 8875; (b) M. H. Keylor, J. E. Park, C.-J. Wallentin and C. R. J. Stephenson, Tetrahedron, 2014, 70, 4264.

23 G. Magagnano, A. Gualandi, M. Marchini, L. Mengozzi, P. Ceroni and P. G. Cozzi, Chem. Commun., 2017, 53, 1591.
24 J. Ohata and Z. T. Ball, Chem. Commun., 2017, 53, 1622.

25 We found that alkyl boronic acids were not reactive under the selected reaction conditions. See also ref. 21.

26 K. D. Collins and F. Glorius, Nat. Chem., 2013, 5, 597.

27 X. Tao, C. G. Daniliuc, O. Janka, R. Pçttgen, R. Knitsch, M. Ryan Hansen, H. Eckert, M. Lübbesmeyer, A. Studer, G. Kehr and G. Erker, Angew. Chem., Int. Ed., 2017, 56, 16641.

28 G. Erdem, C. Öner, A. Mönal, D. Kisakürek and A. Ögüs, J. Biosci., 1994, 19, 9.

29 D. A. Köse and B. Zümreoglu-Karan, New J. Chem., 2009, 33, 1874.

30 L. Liu, N. Xia, Y. Xing and D. Deng, Int. J. Electrochem. Sci., 2013, 8, 11161.

31 S. R. Ali, R. R. Parajuli, Y. Ma, Y. Balogun and H. He, J. Phys. Chem. B, 2007, 111.

32 (a) D. E. Cabelli and B. H. J. Bielski, J. Phys. Chem., 1983, 87, 1809; (b) A. Weissberger, J. E. LuValle and D. S. Thomas Jr., J. Am. Chem. Soc., 1943, 65, 1934.

33 M. Hayyan, M. A. Hashim and I. M. AlNashef, Chem. Rev., 2016, 116, 3029.

34 T. Matsui, Y. Kitagawa, M. Okomura and Y. Shigeta, J. Phys. Chem., 2015, 119, 369-376.

35 J. H. Morris, H. J. Jinsling and D. Reed, Chem. Rev., 1985, 85, 51-76.

36 (a) I. B. Seiple, S. Su, R. A. Rodriguez, R. Gianatassio, Y. Fujiwara, A. L. Sobel and P. S. Baran, J. Am. Chem. Soc., 2010, 132, 13194; (b) G. Yan, M. Yang and W. Xiangmei, Org. Biomol. Chem., 2013, 11, 7999; (c) G.-X. Li, C. A. Morales-Rivera, Y. Wang, F. Gao, G. He, P. Liu and G. Chen, Chem. Sci., 2016, 7, 6407; (d) H. Huang, G. Zhang, L. Gong, S. Zhang and Y. Chen, J. Am. Chem. Soc., 2014, 136, 2280; (e) S. Inagi and T. Fuchigami, Curr. Opin. Electrochem., 2017, 2, 32.

37 F. Lima, U. K. Sharma, L. Grunenberg, D. Saha, S. Johannsen, J. Sedelmeier, E. V. Van der Eycken and S. V. Ley, Angew. Chem., Int. Ed., 2017, 56, 15136.

38 By the point of view of the thermodynamic feasibility of the process, the $E$ values of the DHA $+2 \mathrm{e}^{-}+\mathrm{H}^{+} \rightarrow \mathrm{Asc}^{-}$and $\mathrm{O}_{2}+2 \mathrm{e}^{-}+2 \mathrm{H}^{+} \rightarrow \mathrm{H}_{2} \mathrm{O}_{2}$ are +0.35 (see ref. 34) and +0.695 (P. M. Wood, J. Biochem., 1988, 253, 287) vs. SHE respectively, that makes the process thermodynamically possible. However, these values can be altered by the reaction solvent (in this regard see M. L. Pegis, J. A. S. Roberts, D. J. Wasylenko, E. A. Mader, A. M. Appel and J. M. Mayer, Inorg. Chem., 2015, 54, 11883).

39 S. Wu, W. Waugh and V. J. Stella, J. Pharm. Sci., 2000, 89, 758. 